\title{
A NEW PERSPECTIVE FOR PHYSICAL HEIGHTS IN BRAZIL
}

\section{Uma Nova Perspectiva para as Altitudes Físicas no Brasil}

\author{
Fabio Luiz Albarici ${ }^{1}$ - ORCID: 0000-0003-4436-0561 \\ Ismael Foroughi ${ }^{2}$ - ORCID: 0000-0003-2150-8981 \\ Gabriel do Nascimento Guimarães ${ }^{3}$ - ORCID: 0000-0003-4380-4650 \\ Marcelo Santos ${ }^{2}$ - ORCID: 0000-0001-6354-4601 \\ Jorge Trabanco ${ }^{4}$ - ORCID: 0000-0002-2558-2858 \\ ${ }^{1}$ Instituto Federal do Sul de Minas, Inconfidentes, Minas Gerais, Brasil \\ E-mail: fabio.albarici@ifsuldeminas.edu.br \\ ${ }^{2}$ University of New Brunswick, Fredericton, New Brunswick, Canada \\ E-mail: i.foroughi@unb.ca; msantos@unb.ca \\ ${ }^{3}$ Universidade Federal de Uberlândia, Monte Carmelo, Minas Gerais, Brasil \\ E-mail: gabriel@ufu.br \\ ${ }^{4}$ Universidade Estadual de Campinas, Faculdade de Engenharia Civil, \\ Campinas, São Paulo, Brasil \\ E-mail: trabanco@fec.unicamp.br
}

Received in January $29^{\text {st }} 2018$

Accepted in October $6^{\text {th }} 2018$

Abstract:

The physical heights definition of heights, proposed by Helmert in 1890 is one of the commonly used heights systems in practice. In Helmert's definition, the mean value of gravity along plumbline is computed by simplifying the topography with a Bouguer shell containing masses with mean density value. Although this approximation might be accurate enough many purposes, a more rigorous definition can be determined by considering the effects of terrain, topographic mass density variation, and masses contained in the geoid the mean gravity value along the plumbline. The purpose of this paper is to compute the corrections for the Helmert's definition of the orthometric heights to obtain the rigorous orthometric heights in the state of São Paulo and adjacent states and to evaluate these corrections. The heights system used in Brazil (until July 2018) and some South American countries is normal-orthometric heights, therefore the corrections needs to be applied accordingly. Our numerical results show that there are significant differences between the normal-orthometric and rigorous orthometric heights, with maximum values of $\sim 0.4 \mathrm{~m}$, minimum of $\sim-0.8 \mathrm{~m}$ and mean value of $\sim-0.32 \mathrm{~m}$. There are larger differences between normal-orthometric and normal height than the ones between normal and rigorous definition of orthometric heights.

Keywords: Rigorous Orthometric Heights; Normal Height; Gravity

How to cite this article: ALBARICI, F. L.; FOROUGHI, I.; GUIMARÃES, G. N.; SANTOS, M. and TRABANCO, J. A New Perspective for Physical Heights in Brazil. Bulletin of Geodetic Sciences, 25(1): e2019001, 2019. 


\section{Resumo:}

A definição das altitudes físicas proposta por Helmert em 1890 é um dos sistemas de altitude comumente utilizado na prática. Na definição de Helmert o valor médio da gravidade ao longo do fio de prumo é calculado simplificando a topografia, com Bouguer Shell, contendo um valor médio para a densidade de massas. Embora esta aproximação possa ser bastante acurada para muitos propósitos, uma definição mais rigorosa pode ser determinada considerando os efeitos do terreno, a variação da densidade de massa topográfica e as massas contidas no geoide, para o valor médio da gravidade ao longo do fio de prumo. O objetivo deste artigo é calcular as correções

para a altitude ortométrica de Helmert para obter-se a altitude ortométrica rigorosa para o estado de São Paulo e estados vizinhos, além de avaliar estas correções. No entanto, o sistema de altitude utilizado no Brasil (até julho de 2018) e em alguns países da América do Sul é a normalortométrica, portanto as correções precisam ser aplicadas corretamente. Os resultados numéricos mostram que existem diferenças significativas entre as altitudes normal-ortométrica e rigorosa, com valores máximos de 0,4 m, mínimo de -0,8 m e valor médio de -0,32 m. Encontram-se as maiores diferenças entre as altitudes normal-ortométrica e normal do que entre a altitude normal e a definição mais rigorosa de altitude.

Palavras-chave: Altitude ortométrica Rigorosa; Altitude Normal; Gravidade

\section{Introduction}

Over the past decades, South American countries, among others, have been trying to modernize their height systems based on physical definition of heights. Usually, the heights systems in these countries are characterized as normal or orthometric, which are assumed to be the best solution for a height system without gravimetric corrections. A height system consists of two components: a datum and the definition of heights above the datum. Foroughi et al. (2017) compared the two commonly used height systems, i.e. classical and normal, and showed that the classical height system, including geoid and orthometric heights has the best congruency among other systems and therefore it is recommended to use if physical heights are required. If geoid is used as the height datum, the most compatible physical height to this datum is rigorous orthometric heights. A simplified version of rigorous orthometric heights is Helmert's orthometric heights which approximates the topography above geoid by a Bouguer shell and assumes the topography has mean density value everywhere. According to Santos et al. (2006) the five corrections applied to Helmet's orthometric height to get rigorous orthometric heights are complicated to compute and the required data are difficult to collect but recently Foroughi et al. (2018) presented that the data required to compute these corrections are freely available nowadays and reported the advantages of the using rigorous orthometric height rather normal heights. The data required for correcting the Helmert's to rigorous orthometric heights are the same used to calculate the gravimetric geoid model, in this way, the orthometric rigorous heights are more compatible with the geoid model, provided that the same corrections are applied from the same data.

According to the Brazilian Institute of Geography and Statistics (IBGE, 2011), geoid is selected as height system and the only correction applied to the equipotential surfaces for the levelling networks were corrections for non-parallelism. The leveling data were observed, adjusted and corrected from the term applied to the topographic irregularities observed in Equation 1, 
which reduces the error caused by the non-parallelism of the equipotential surfaces. The parallelism correction is not required for levelling sights shorter than ( $100 \mathrm{~m}$ ) or for levelling sections shorter than $(\sim 3 \mathrm{~km})$. At larger distances the equipotential surfaces are not parallel; the reason is that the Earth's mass distribution is not homogeneous (Freitas e Blitzkow, 1999). This correction is performed due to the lack of gravimetric data available. The non-parallelism correction to spirit leveling reads (Pina et al. 2006):

$$
C_{o}=-\frac{H_{m}\left(C_{1} \sin 2 \varphi_{m}+2 C_{2} \sin 4 \varphi_{m}\right) \Delta_{\varphi}}{\left(1+C_{1} \sin ^{2} \varphi_{m}+C_{2} \sin ^{2} 2 \varphi_{m}\right)}
$$

where: $H_{m}$ is the mean height of the leveling section; $\varphi_{m}$ is the latitude of the section; $\Delta_{\varphi}$ represents the difference between the section latitudes; $C_{1}$ and $C_{2}$ are the coefficients of the normal gravity field, where the values are 0.0053023655 and -0.0000059 , respectively.

The correction presented in Equation 1 results in the normal-orthometric for the heights of the Brazilian High-Precision Altimetric Network (RAAP - Rede Altimétrica de Alta Precisão). This type of height replaces the use of the real Earth potential $(W)$, by using the normal potential $(U)$. Thus, the geopotential numbers (C) are replaced by the numbers of normal potential (Filmer et al. 2010). There are several definitions of normal-orthometric heights which were discussed in Filmer et al. (2010). They also investigated the differences between normal-orthometric and normal heights for Australian network.

Tenzer et al, (2005) derived the spatial formulas for corrections to the normal heights to calculate the rigorous orthometric height, corresponding corrections to the Helmert orthometric heights were derived in Santos et al. (2006). The differences between normal and Helmert's orthometric heights have already been computed in some areas of the world, e.g. Allister and Featherstone (2001); Kingdon et al. (2005); Odera and Fukuda (2015); Foroughi et al. (2015); Tenzer et al. (2017), and Foroughi and Tenzer (2017).

In the present paper, the spatial method proposed by Santos et al. (2006) was used to compute the corrections to the Helmert orthometric heights of the GNSS/leveling points in the state of São Paulo and surrounding. Some of available spectral models were also employed for faster computation. We also analyzed the differences between the rigorous and Helmert's orthometric heights with the normal-orthometric heights of the Brazilian Geodetic System and there was a significant difference.

The height network of Brazil has been always readjusted, the latest adjustment was done in 2011 and from July 2018 a new readjustment was performed, using gravimetric data to improve the accuracy of the system. Now, the Brazilian geodetic system uses the normal height. The results of this study can be used to analyze the behavior of the network.

\section{Theory Review}

The quest for adequate representation of heights is not trivial and an appropriate setting of a vertical reference is essential for many applications (Vaníček et al. 2003). Historically, for the definition of heights, various approximations of the mean value of gravity along the plumbline 
between geoid and Earth's surface were used. Therefore, the modeling of the differences between these approximations is necessary to compute the differences in heights, although there may be in the future a univocal reference to the geopotential numbers (Ferreira et al. 2011). According Tenzer (2005), the main problem of the rigorous definition of the orthometric height is the evaluation of the mean value of the Earth's gravity acceleration along the plumbline within the topography. Figure 1 illustrates the differences between heights:

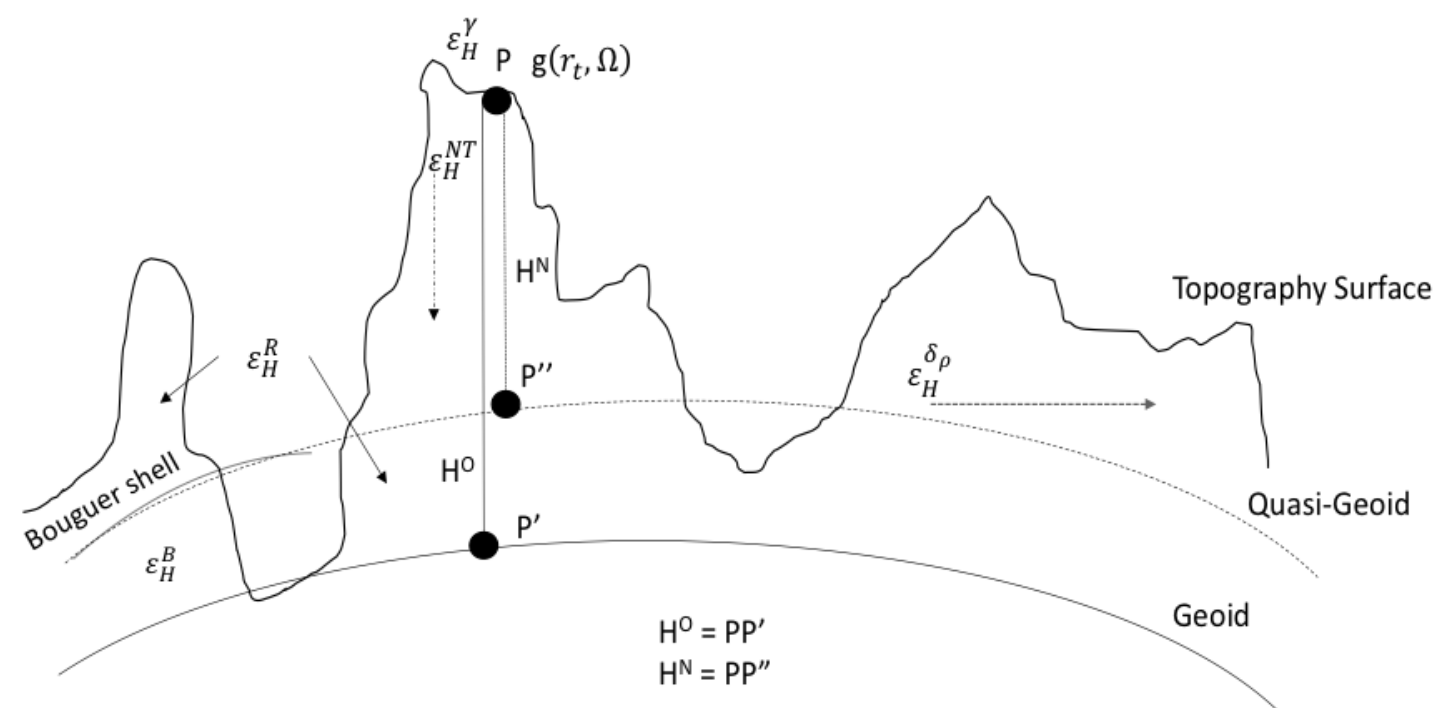

Figure 1: Topography, Normal and Orthometric Heights (source: the author).

\subsection{Geopotential Number}

Height systems are still an ongoing discussion between geodesist, especially those involved with its determination and use. Blitzkow et al. (2007) argues that the concept of height is related to the boundary value problems of physical geodesy. Consequently, the concept cannot be considered only from the geometric point of view, but especially from a physical perspective. There is no direct geometric relationship between the result of leveling and the orthometric height (Hofmann-Wellenhof; Moritz, 2006 Sec 4). The different heights used in geodetic sciences include: orthometric, normal, dynamic and recently, the rigorous orthometric height. These heights are a function of geopotential number $(C)$. The geopotential number, defined as the difference between the potential on the geoid $\left(W_{0}\right)$ and the potential at surface point $\left(W_{p}\right)$, is determined from observed gravity and height difference between that point and mean sea level, realized at the surface of the Earth (Kingdon et al. 2005; Sánchez, 2013). If the measurements of gravity are performed in conjunction with the leveling, we have (Freitas; Blitzkow, 1999):

$$
W_{0}-W_{P}=C \cong \sum_{0}^{P} g \delta_{n},
$$

where: $\delta_{n}$ is the level difference between two points. If continuous points are observed between two points, then the sum can be replaced by an integral: 


$$
W_{0}-W_{P}=C \cong \int_{0}^{P} g \delta_{n}
$$

\subsection{Helmert Orthometric Height}

Several types of heights can be defined from the different definition of potential differences between two points and different definition of the integral mean gravity along the plumb line. The orthometric height $\left(H^{o}\right)$ is mathematically defined by the geopotential number $(C)$ divided by the mean gravity $\left(g_{m}\right)$ between the point of interest and the geoid (Kingdon et al. 2005).

$$
H^{o}=\frac{C}{g_{m}}
$$

where

$$
g_{m}=\frac{1}{H^{o}} \int_{P_{0}}^{P} g d H
$$

Equation 4 requires knowledge of the geopotential number and the mean acceleration of gravity along the plumbline. None of these are directly measurable, but there exists a relation between leveling differences $\left(\Delta v_{A B}\right)$ and the orthometric height differences $(\Delta H)$. The difference of orthometric heights of two points is the same as the difference in geometric height (spirit leveling) plus a correction factor known as orthometric correction:

$$
\Delta H_{A B}=\Delta v_{A B}+O C_{A B}
$$

where: $O C_{A B}$ is the orthometric correction, and presents the following form (Heiskanen; Moritz, 1967, Eq. 4-33):

$$
O C_{A B}=\sum_{B}^{A} \frac{g_{i}-\gamma_{0}}{\gamma_{0}} \delta_{v_{i}}+\frac{\bar{g}_{A}-\gamma_{0}}{\gamma_{0}} H A+\frac{\bar{g}_{B}-\gamma_{0}}{\gamma_{0}} H B
$$

where: $g_{i}$ is the gravity observed at the stations; $\bar{g}_{A}$ and $\bar{g}_{B}$ are the mean values of gravity along the plumbline in $A$ and $B ; \gamma_{0}$ is an arbitrary constant, considered as the value of normal gravity for the latitude of $45^{\circ}$.

Helmert orthometric correction (like any other correction, such as dynamic or normal) is not a function of levelling section length but a function of what type of height one is interested in. Therefore, if one is interested in just levelled heights, no correction is necessary. If one is interested in Helmert orthometric heights, then orthometric correction needs to be applied. It is usually applied to the levelled section between bench marks, not to the intermediary setups. Within a $2 \mathrm{~km}$ section, the Helmert orthometric correction may vary between 0 to $1.4 \mathrm{~mm}$ (Heiskanen; Moritz, 1967). 


\subsection{Normal Height}

Molodensky [1945; 1948], suggested the use of normal heights to avoid the requirement of knowledge of topographical density inside the Earth. Normal height is an alternative to orthometric heights, describing the heights on a fictitious surface, the quasi-geoid. The normal height $\left(H^{N}\right)$ requires the use of a quantity known as height anomaly $(\square)$. The height anomaly is defined as the distance along the normal plumbline between the quasi-geoid and the reference ellipsoid, or, as the distance between the surface of the Earth and the Telluroid. These anomalous heights are also sometimes called "quasi-geoid heights" (Vaníček et al. 2003).

Equation 8 can be used iteratively to determine the Molodensky normal height (Heiskanen; Moritz, 1967):

$$
H^{N}=\frac{C}{\gamma_{0}+a H^{N}+b\left(H^{N}\right)^{2}}
$$

where: $\gamma_{0}$ is the normal gravity on the reference ellipsoid and the coefficients $a \approx$ $-0.1543 \times 10^{3} \mathrm{mGal} / \mathrm{km}$ and $b \approx 0.024 \times 10^{3} \mathrm{mGal} / \mathrm{km}^{2}$.

According to Hofmann-Wellenhof and Moritz (2006) assuming the gravity field of the Earth becomes normal, i.e., $\mathrm{W}=U, g=\gamma, \mathrm{T}=0$ (disturbing potential), the normal heights are defined as:

$$
\begin{aligned}
& C=\int_{0}^{H^{N}} \gamma d H^{N}, \\
& C=\bar{\gamma} H^{N},
\end{aligned}
$$

where: $H^{N}$ is the normal height and $\gamma$ is the normal gravity.

Equations 9 and 10 are identical to the orthometric height equation (Equation 4 and 5), but their meaning is completely different. The zero used is for the reference on the ellipsoid, thus, the normal height depends on the choice of the ellipsoid and of the geodetic datum. Normal gravity is an analytical function and its mean can be calculated without any observation. From the definition of the normal height $H^{N}$, it can be seen that it is the height of the ellipsoid where the normal gravity potential is equal to the real geopotential of the point of interest (Meyer et al. 2006). Normal heights can be determined from the differences of geometric heights observed by differential leveling and applying gravimetric corrections. The correction term presents the same structure as the term described for the orthometric correction, i.e.:

$$
N C_{A B}=\sum_{A}^{B} \frac{g_{i}-\gamma_{0}}{\gamma_{0}} \delta_{v_{i}}+\frac{\bar{\gamma}_{A}-\gamma_{0}}{\gamma_{0}} H A^{N}+\frac{\bar{\gamma}_{B}-\gamma_{0}}{\gamma_{0}} H B^{N}
$$


where: $N C_{A B}$ is the normal correction, $\bar{\gamma}_{A}$ and $\bar{\gamma}_{B}$ are the normal gravities of $\mathrm{A}$ and $\mathrm{B}$, respectively.

\subsection{Normal-Orthometric Height}

The correction presented in equation (1) links RAAP to a reference type known as normalorthometric. The normal-orthometric heights, have the same characteristic of normal and orthometric heights usually comprised of a correction applied to the leveling observations. The general concept of normal-orthometric heights is that the normal gravity potential $(U)$ completely replaces the gravity field potential $(W)$, with the geopotential numbers $(C)$ replaced by normal potential numbers $C^{N}$ (Filmer et al. 2010).

$$
C^{N}=U_{P}-U_{N O}
$$

where $U_{P}$ is normal potential at the topographic surface and $U_{N O}$ is normal potential at the reference surface. The normal orthometric heights are calculated by equation 13 .

$$
H^{N O}=\frac{C^{N}}{\bar{\gamma}} \text {. }
$$

Normal orthometric heights were planned as an approximation of $H^{o}$, in areas where observations of gravity are insufficient. There are numerous types of normal-orthometric corrections, mentioned in Bomford (1980) as well as Amos and Featherstone (2009) and Filmer et al. (2010). The correction term presented in Ferreira (2011) is:

$$
N O C_{A B}=-\frac{f}{R} \sum_{B}^{A} H_{A}^{N O} \cdot \sin 2 \bar{\varphi} \cos \alpha_{A B} \cdot \delta_{S_{A B}}+\cdots
$$

where $f$ is a constant relative to the normal "flatness of gravity"; $R$ is the mean earth radius; $H_{A}^{N O}$ is the height for the starting point $A ; \bar{\varphi}$ is the mean latitude between points $A$ and $B ; \alpha$ azimuth between points $A$ and $B ; \delta s$ is the horizontal distance between points $A$ and $B$.

\subsection{Rigorous Determination of Orthometric Heights}

Foroughi et al. [2017, 2018] showed that the rigorous orthometric heights can be determined using data sets freely available and with high accuracy. The corrections to convert the Helmert orthometric heights into rigorous orthometric heights are found in Santos et al. (2006) and Foroughi et al. (2017); namely: the second-order correction to normal gravity, the effects of Bouguer shell, terrain/roughness correction, variable topographic density correction and nontopographic correction (Tenzer et al.2005; Santos et al.2006). The mean gravity given by equation 15 is more rigorous than the approximated value of Helmert's definition. The difference is called correction to the mean value of Helmert $\varepsilon_{\bar{g}}(\Omega)$ (Equation 17). This correction can be applied to Helmert orthometric height with accuracy of less than one millimeter: 


$$
\begin{gathered}
\bar{g}(\Omega) \approx \bar{\gamma}(\Omega)+\overline{\delta g}^{N T}(\Omega)+\bar{g}_{B}^{T}(\Omega)+\bar{g}_{R}^{T}(\Omega)+\bar{g}^{\delta \rho}(\Omega) \\
\bar{g}^{H}(\Omega)=\gamma\left(r_{t}, \Omega\right)+\delta_{g}^{N T}\left(r_{t}, \Omega\right)+g_{B}^{T}\left(r_{t}, \Omega\right)+g_{R}^{T}\left(r_{t}, \Omega\right)+g^{\delta \rho}\left(r_{t}, \Omega\right)-1 / 2\left(\frac{\delta \gamma}{\delta h}+\right. \\
\left.4 \pi G \rho_{0}\right) H^{o}(\Omega) \\
\varepsilon_{\bar{g}}(\Omega)=\bar{g}(\Omega)-\bar{g}^{H}(\Omega)=\left[\bar{\gamma}(\Omega)-\gamma\left(r_{t}, \Omega\right)+1 / 2 \frac{\delta \gamma}{\delta h} H^{o}(\Omega)\right]+\left[\bar{g}_{B}^{T}(\Omega)-g_{B}^{T}\left(r_{t}, \Omega\right)+\right. \\
\left.2 \pi G \rho_{0} H^{o}(\Omega)\right]+\left[\overline{\delta g}^{N T}(\Omega)-\delta_{g}^{N T}\left(r_{t}, \Omega\right)\right]+\left[\bar{g}_{R}^{T}(\Omega)-g_{R}^{T}\left(r_{t}, \Omega\right)\right]+\left[\bar{g}^{\delta \rho}(\Omega)-g^{\delta \rho}\left(r_{t}, \Omega\right)\right]
\end{gathered}
$$

where: $G$ is Newton's gravitational constant, $\Omega$ represents the geocentric spherical coordinates $(\phi, \lambda), r_{t}(\Omega)$ is the geocentric radius of the Earth, $R$ is the inner radius of the shell, $H^{o}(\Omega)$ is the orthometric height, $\overline{\delta g}^{N T}$ is the mean geoid-generated gravity disturbance. $\delta_{g}^{N T}\left(r_{t}, \Omega\right)$ is the gravity generated by the masses within the geoid, $\bar{g}_{R}^{T}(\Omega)$ is the mean gravitation value generated by the roughness of the terrain, $g_{R}^{T}\left(r_{t}, \Omega\right)$ is the gravitation generated by the terrain roughness, $g^{\delta} \rho\left(r_{t}, \Omega\right)$ is the effect on gravitation due to lateral mass and density variations within the topography regarding the reference value of $\rho_{0}=2.670 \mathrm{kgm}^{-3}, \varepsilon_{\bar{g}}(\Omega)$ correction to Helmert's mean gravity.

Equation 17 represents the differences between mean gravity in Helmert's definition and rigorous definition. This difference can be applied to Helmert orthometric heights to get rigorous orthometric heights (see, Eq. 4). Each of the terms in Eq. (17) is translated to the height correction and defined as follows (Tenzer et al. (2005), Santos et al. (2006) and Foroughi and Tenzer (2017)). $\left(\varepsilon_{H}^{\gamma}\right)$ is:

The correction due to considering the second approximation term of the normal gravity

$$
\varepsilon_{H}^{\gamma}(\Omega)=-\frac{\gamma H^{o^{3}}(\Omega)}{g^{H}(\Omega) a^{2}}
$$

The correction due to second term of Bouguer shell correction reads:

$$
\varepsilon_{H}^{B}(\Omega)=\frac{4}{3} \pi G \rho_{0} \frac{H^{o}(\Omega)^{2}}{R+H^{o}(\Omega)}\left(2-\frac{H^{o}(\Omega)}{R+H^{o}(\Omega)}\right)
$$

This is the more rigorous formulation for the sphericity of Bouguer shell, where $r$ and $H$ are along the same radial (i.e., $H^{o}(\Omega)=r_{t}, \Omega-r_{g}, \Omega$ ).

The third correction is for the geoid-generated gravity disturbance. The correction to Helmert orthometric height due to the geoid-generated gravity disturbance (no-topography correction), comprising the mean value along the plumbline $\overline{\delta g}^{N T}(\Omega)$ and the value in the surface of the Earth $\delta_{g}^{N T}\left(r_{t}, \Omega\right)$ is:

$$
\varepsilon_{H}^{N T}(\Omega)=\frac{1}{g^{H}(\Omega)}\left(H^{o}(\Omega) \delta^{N T}\left(r_{t}, \Omega\right)-\overline{\delta g}^{N T}(\mathrm{r}, \Omega)\right)
$$


The mean No-Topography gravity disturbances in Eq. (20) may computed by (Santos et al.2006):

$$
\overline{\delta g}^{N T}(\mathrm{r}, \Omega)=\frac{1}{4 \pi} \frac{R}{H^{o}(\Omega)} \iint_{\Omega^{\prime} \in \Omega_{o}} \bar{K}\left[R+H^{o}(\Omega), \psi\left(\Omega, \Omega^{\prime}\right), R\right] \times \delta_{g}^{N T}\left(R, \Omega^{\prime}\right) d \Omega^{\prime}
$$

where: $\bar{K}$ represents the intermediate integration core of Kernel of the downward continuation.

In the second part of the equation 21, the no-topography gravity anomaly on the geoid is required, thus the free-air anomaly correction is used to determine the no-topography gravity anomaly and finally to determine the no-topography gravity disturbance (geoid). This process is very accurate but also very demanding.

A second option, in which the process is also accurate but less demanding, is use of the Earth Gravitational Model (EGM). This option removes the effect of topography, thus providing the no-topography gravity anomaly (geoid). For this the Equation 22 was used, obtained in Tenzer et al. (2015) and Foroughi and Tenzer (2017). To calculate the effect of topography (topographic surface, ice, lakes, sediments and earth crust) the spherical harmonic coefficients are used. The no-topography potential disturbance $\left(T^{N T}\right)$ is defined on the topographic surface $\left(r_{t}, \Omega\right)$, subtracting the topographic potential $\left(V^{T}\right)$ to the potential disturbance $(T)$.

$$
T^{N T}=T\left(r_{t}, \Omega\right)-V_{e}^{T, \rho^{T}}\left(r_{t}, \Omega\right)-\sum_{j} V_{e j}^{\delta \rho}\left(r_{t}, \Omega\right)
$$

where: $j$ is the summation index of the density contrast layers in volumetric mass applied to describe the anomalous density distribution within the entire topography. Earth 2014 topographic model (Hirt and Rexer, 2015) and EIGEN-6C4 (Förste, et al.2014) were employed to analyze the NT-disturbing potentials coefficients.

The Helmert orthometric height model neglects the effects of terrain/roughness, thus the correction to Poincaré-Pray model is:

$$
\begin{gathered}
\varepsilon_{H}^{R}(\Omega)=\frac{G \rho_{0}}{g^{H}(\Omega)}\left(\left.H^{o}(\Omega) \iint_{\Omega^{\prime} \in \Omega_{0}} \int_{r^{\prime}=R+H^{o}(\Omega)}^{r^{\prime}=R+H^{o}\left(\Omega^{\prime}\right)} \frac{\partial l^{-1}\left(r, \Omega, r^{\prime}, \Omega^{\prime}\right)}{\partial r}\right|_{r=R+H^{o}(\Omega)} \times r^{\prime^{2}} d r^{\prime} d \Omega^{\prime}-\right. \\
\left.\iint_{\Omega^{\prime} \in \Omega_{0}} \int_{r^{\prime}=R+H^{o}(\Omega)}^{\left.r^{\prime}=R+\Omega^{\prime}\right)}\left(l^{-1}\left[R, \Omega, r^{\prime}, \Omega^{\prime}\right]-l^{-1} \times\left[R+H^{o}(\Omega), \Omega, r^{\prime}, \Omega^{\prime}\right]\right) r^{\prime 2} d r^{\prime} d \Omega^{\prime}\right)
\end{gathered}
$$

A constant topographic mass density is assumed, in which the gravitational field of the terrain roughness term is not harmonic within the topography. Thus, it must be calculated from a model adopted from the topography's shape (i.e., a DTM - Digital Terrain Model), combined with a constant of mass density.

The correction for the Helmert orthometric height using the information on the variation of lateral density of topographic masses, i.e., masses above the geoid, is determined using Equation 24: 


$$
\begin{gathered}
\varepsilon_{H}^{\delta_{\rho}}(\Omega)=\frac{G}{g^{H}(\Omega)}\left(H^{o}(\Omega) \iint_{\Omega^{\prime} \in \Omega_{0}} \int_{r^{\prime}=R+H^{o}(\Omega)}^{r^{\prime}=R+H^{o}\left(\Omega^{\prime}\right)} \delta_{\rho}\left(r^{\prime}, \Omega^{\prime}\right) \times\left.\frac{\partial l^{-1}\left(r, \Omega, r^{\prime}, \Omega^{\prime}\right)}{\partial r}\right|_{r=R+H^{o}(\Omega)}{r^{\prime}}^{2} d r^{\prime} d \Omega^{\prime}-\right. \\
\left.\iint_{\Omega^{\prime} \in \Omega_{0}} \int_{r^{\prime}=R+H^{o}(\Omega)}^{r^{\prime}=R+H^{o}\left(\Omega^{\prime}\right)} \delta_{\rho}\left(r^{\prime}, \Omega^{\prime}\right)\left(l^{-1}\left[R, \Omega, r^{\prime}, \Omega^{\prime}\right]-l^{-1}\left[R+H^{o}(\Omega), \Omega, r^{\prime}, \Omega^{\prime}\right]\right) r^{\prime 2} d r^{\prime} d \Omega^{\prime}\right) .
\end{gathered}
$$

The assessment of the geoid using GNSS/leveling points is more accurate after the conversion of the Helmert orthometric height to rigorous orthometric height. Finally, the complete equation for the correction to Helmert orthometric height (Santos et al. 2006 and Foroughi et al. 2017):

$$
\varepsilon_{H^{o}}(\Omega)=\varepsilon_{H}^{\gamma}(\Omega)+\varepsilon_{H}^{B}(\Omega)+\varepsilon_{H}^{N T}(\Omega)+\varepsilon_{H}^{R}(\Omega)+\varepsilon_{H}^{\delta_{\rho}}(\Omega)
$$

where: $\varepsilon_{H^{o}}$ is the correction to Helmert orthometric heights to convert it to rigorous orthometric height (Tenzer et al. 2005).

\section{Methodology}

The data were obtained from the Institute of Astronomy, Geophysics and Atmospheric Sciences of São Paulo University (IAG/USP). The study area is located between the latitudes $-19^{\circ}$ and $-26^{\circ}$ and longitudes $-54^{\circ}$ and $-44^{\circ}$. It contains 155 points distributed throughout the state of São Paulo and neighboring states. These points belong to the RAAP, which is part of the Brazilian Geodetic System (SGB - Sistema Geodésico Brasileiro). The Brazilian geodetic system is compatible with the geodetic system used by the countries of South America, SIRGAS2000. Its realization is the regional densification of the International Terrestrial Reference Frame (ITRF) in Latin America and the Caribbean (SIRGAS, 2018). GRS80 (Geodetic Reference System 1980), is the geodetic reference system, as established by the IAG (International Association of Geodesy) and it is considered identical to WGS84 (IBGE, 2015). The topographical heights in the study area vary between 0 and 1200 meters and most of the control points are located in the São Paulo state where the topography inside the state is smooth. The available data of the control points contain: latitude, longitude, geodetic heights, normal height from leveling, ground gravity observations, and density model of topographic masses. Figure 2 shows the location of the points in the study area. 


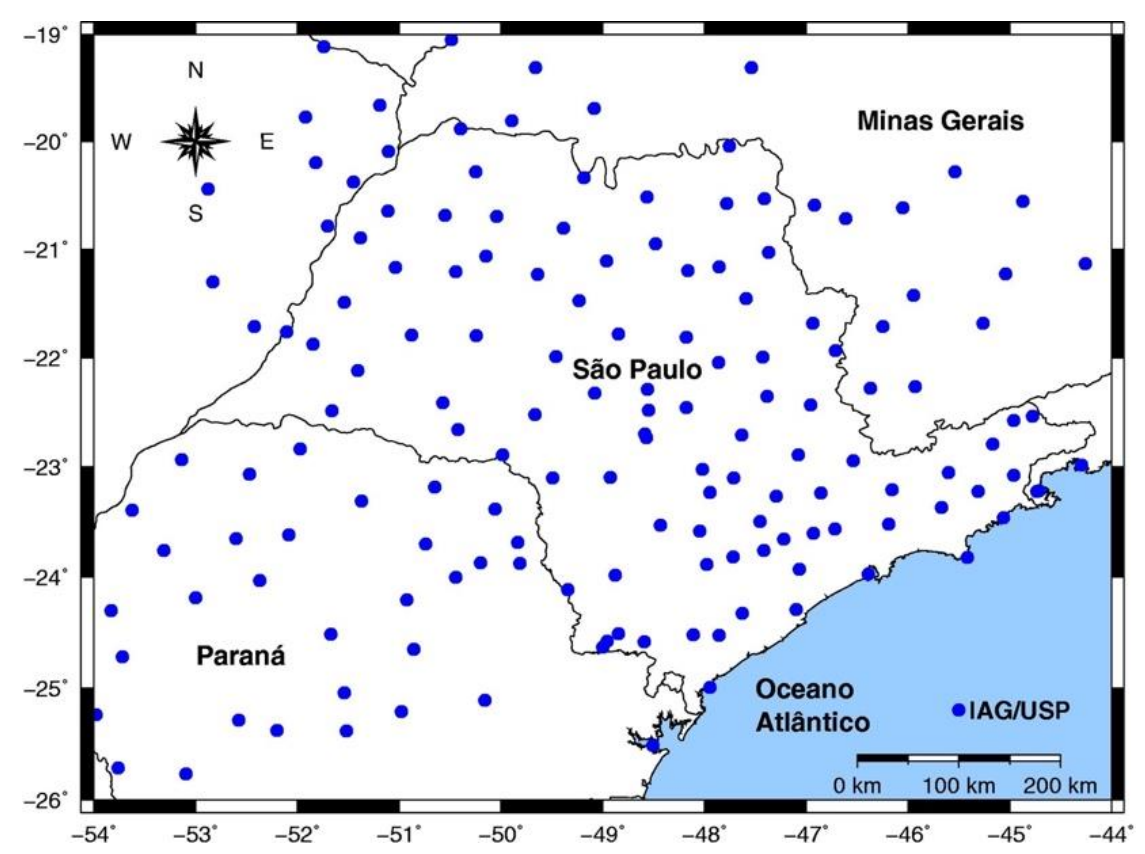

Figure 2: Location of the test area (source: the author)

To calculate the geoid-generated gravity disturbance the data required are: the topographic data ACE2 (Altimeter Corrected Elevations) with an extended strip border of $3^{\circ}$ of the original area, (http://tethys.eaprs.cse.dmu.ac.uk/ACE2/shared/webdownload_5mins), the area is located between $-26^{\circ}$ and $-19^{\circ}$ in latitude and $-56^{\circ}$ and $-41^{\circ}$ in longitude. Figure 3 illustrates the topography and Figure 4 shows the result for the No-Topography gravity disturbances. The input data used for the correction of lateral density and terrain/roughness were the DTM (Digital Terrain Model) of 3", 30" and 5', and the global models of DDM (Digital Density model) of 30" for the state of São Paulo, Brazil (Foroughi et al. 2017). Figure 5 (a) and (b) illustrate the DTM and DDM models, respectively.

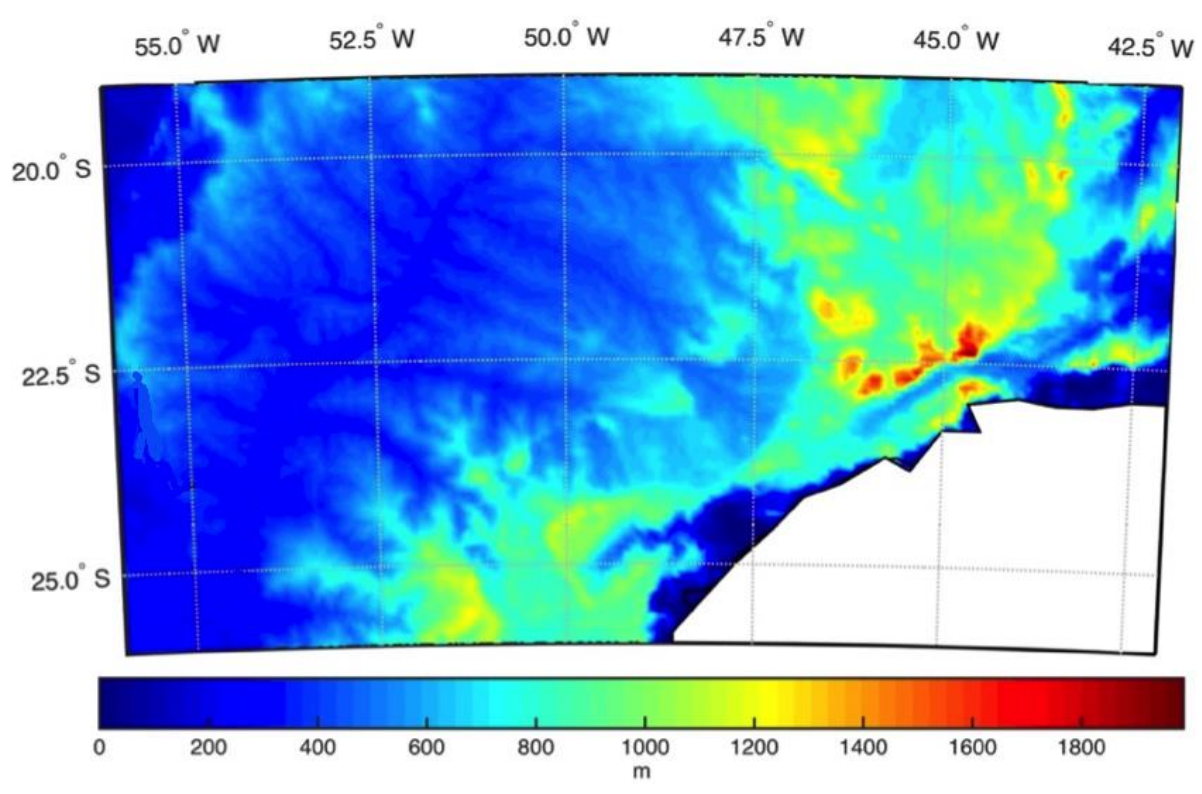

Figure 3: Topographic surface ACE2 


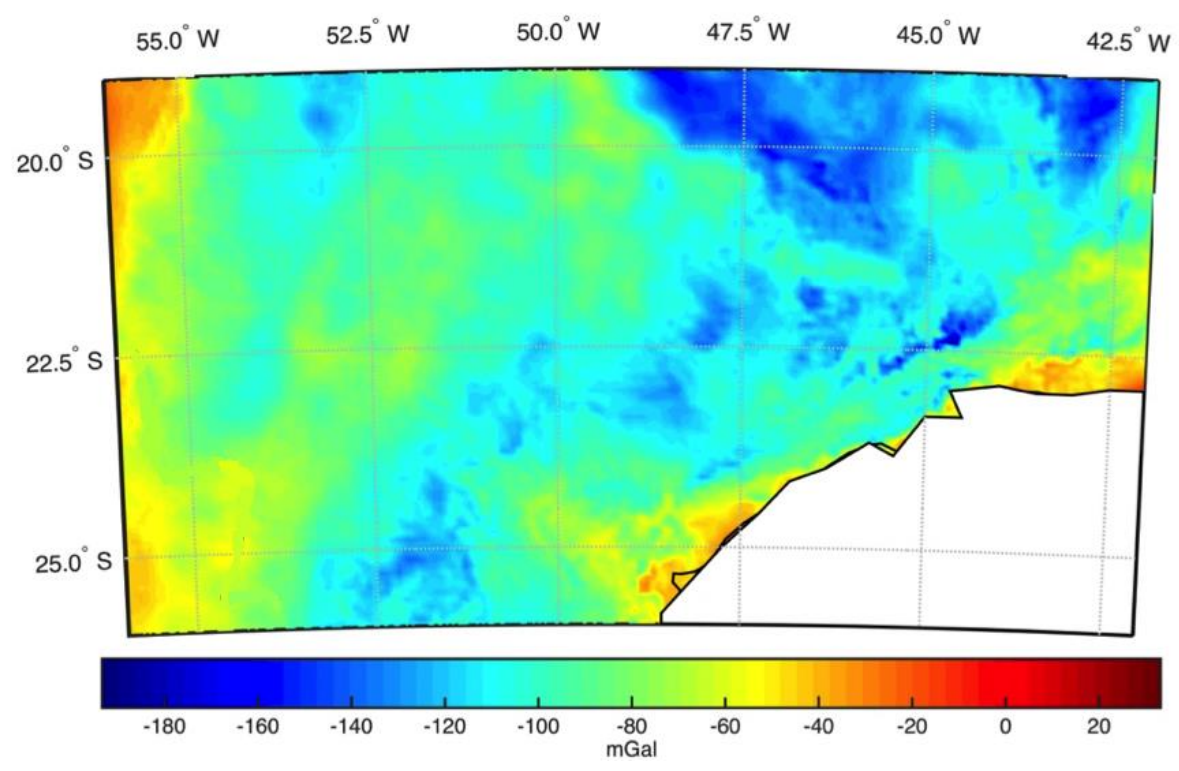

Figure 4: No-Topography gravity disturbance
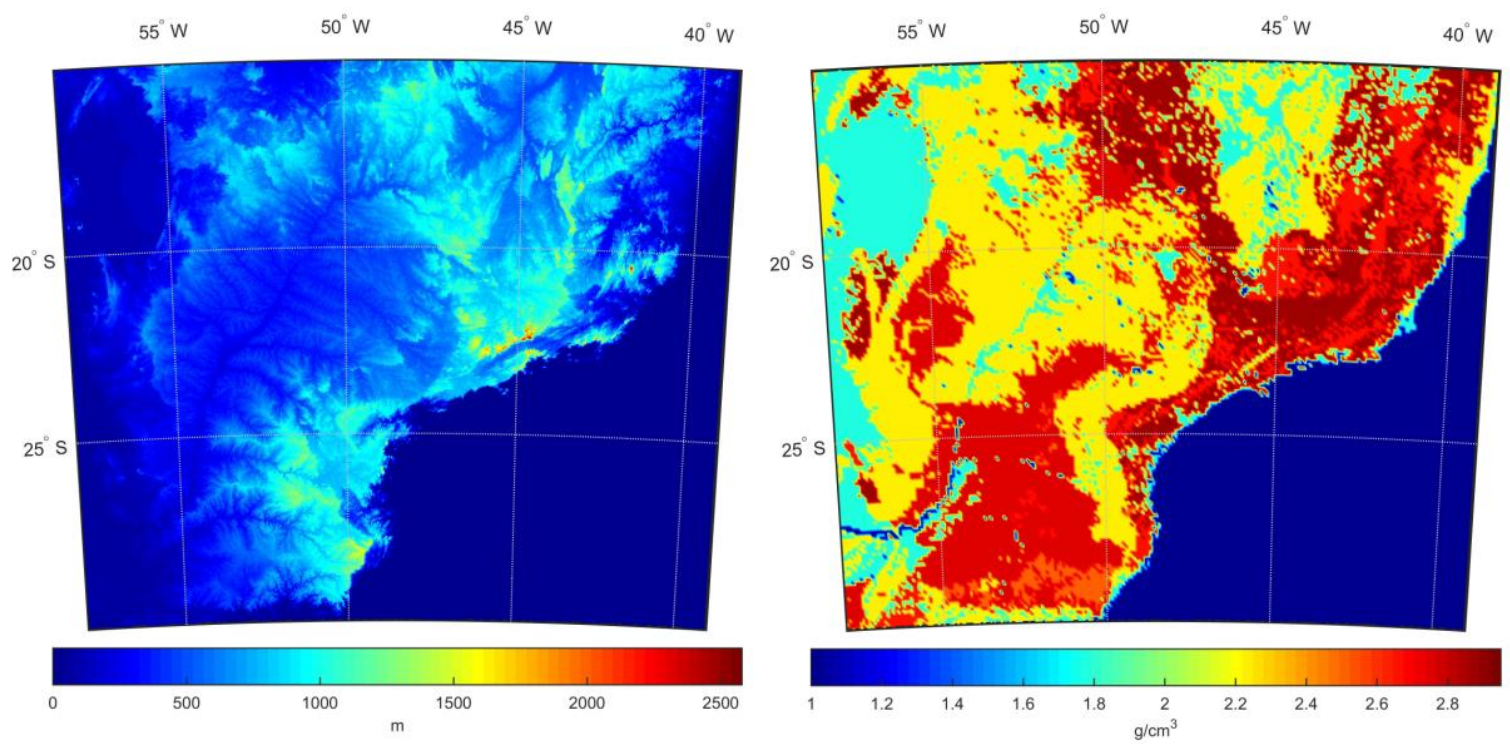

Figure 5: (a) Digital Terrain Model, (b) Digital Density Model

The DDM model is required to calculate the lateral density variation correction to the Helmert orthometric heights, the DTM is required for the terrain/roughness correction.

The procedure was: first, the geopotential number was calculated by Equation 3 where the mean gravity was evaluated between the bench marks, in this way one could compute the normal heights $\left(H^{N}\right)$ and Helmert's orthometric height $\left(H^{O}\right)$ and then apply the five corrections to the Helmert's orthometric heights to obtained the rigorous orthometric height $\left(H^{R O}\right)$. Second, we compared the differences between the normal-orthometric $\left(H^{N O}\right)$ and the Helmet's orthometric heights and the rigorous orthometric heights, to verify the impact of the corrections applied in the São Paulo state. 
Third, we used the normal-orthometric heights provided by institution (IBGE - Instituto Brasileiro de Geografia e Estatística) and we analyze its differences with Helmert's and rigorous orthometric height. Finally, we analyze which of these two systems (Normal-Orthometric or Rigorous Orthometric height) has the smallest difference with the Normal height.

\section{Results and Discussion}

The corrections were calculated separately (Equations 18, 19, 20, 23 and 24) and each equation contributed to the corrections. Table 1 shows that the first two corrections (secondorder for normal gravity and Bouguer shell) present very negligible and can be ignored, but they were used in this paper. These two corrections are directly related to the topography. Santos et al.2006 and Kingdon et al.2005 reported that for the largest mountain in the world, i.e. is $8.8 \mathrm{~km}$, these corrections are of $\varepsilon_{H}^{\gamma}=1.5 \mathrm{~cm}$ and $\varepsilon_{H}^{B}=-1.6 \mathrm{~cm}$. Therefore, these corrections can be ignored in some parts of the world. However, the most important corrections to obtain the rigorous orthometric height are the geoid-generated gravity disturbance $\left(\varepsilon_{H}^{N T}\right)$, the terrain/roughness-generated gravity $\left(\varepsilon_{H}^{R}\right)$ and the lateral variation of topographical mass density $\left(\varepsilon_{H}^{\delta_{\rho}}\right)$. Table 1 summarizes the statistics obtained for each correction. The results of each correction are presented in Figure 6, where the behavior of each correction in every point used can be verified.

Table 1: Statistics for each correction Helmert Orthometric heights

\begin{tabular}{c|c|c|c|c|c|c}
\hline $\begin{array}{c}\text { Corrections for } \\
\text { Orthometric height } \\
(\mathrm{mm})\end{array}$ & $\varepsilon_{H}^{\gamma}$ & $\varepsilon_{H}^{B}$ & $\varepsilon_{H}^{N T}$ & $\varepsilon_{H}^{R}$ & $\varepsilon_{H}$ & $\begin{array}{c}\text { Total } \\
\text { Correction }\end{array}$ \\
\hline Minimum & $-3.1 \times 10^{-4}$ & $-3 \times 10^{-4}$ & $-9 \times 10^{-4}$ & -10.695 & -17.099 & -27.795 \\
Maximum & 0.000 & 0.000 & $3.4 \times 10^{-3}$ & 4.619 & 9.092 & 13.714 \\
Mean & $-7 \times 10^{-4}$ & $-6 \times 10^{-4}$ & $5.3 \times 10^{-4}$ & -1.313 & -2.964 & -4.277 \\
Standard deviation $( \pm)$ & $7 \times 10^{-4}$ & $6 \times 10^{-4}$ & $8 \times 10^{-4}$ & 2.206 & 4.880 & 7.088 \\
\hline
\end{tabular}

The results of each correction show that $\varepsilon_{H}^{\gamma}$ and $\varepsilon_{H}^{B}$ have similar and very small values, with maximum of 0 , minimum $-0.00031 \mathrm{~mm}$, mean of $-0.0007 \mathrm{~mm}$ and standard deviation of 0.0007 $\mathrm{mm}$. The third correction $\left(\varepsilon_{H}^{N T}\right)$ presents the values of maximum, minimum, mean and standard deviation of $0.0034 \mathrm{~mm},-0.0009 \mathrm{~mm}, 0.00054 \mathrm{~mm}$ and $0.0008 \mathrm{~mm}$, respectively. The fourth correction $\left(\varepsilon_{H}^{R}\right)$ presented maximum and minimum values of $4.6 \mathrm{~mm}$ and $-10.6 \mathrm{~mm}$ and with mean and standard deviation values of $-1.31 \mathrm{~mm}$ and $2.2 \mathrm{~mm}$, respectively. The lateral density correction $\left(\varepsilon_{H}^{\delta_{\rho}}\right)$ is the largest correction, with the maximum value of $9.09 \mathrm{~mm}$, minimum of $17.09 \mathrm{~mm}$, mean of $-2.9 \mathrm{~mm}$ and standard deviation of $4.8 \mathrm{~mm}$. According to Albarici et al. (2017), in a study conducted in the city of Campinas, São Paulo, the lateral density had major influence. However, the values presented were biggest for mean of $-5.7 \mathrm{~mm}$ and smaller for standard deviation of $4.2 \mathrm{~mm}$, with maximum and minimum values of $2.7 \mathrm{~mm}$ and $-12.8 \mathrm{~mm}$. Figure 6 illustrates the major corrections along the area used. 

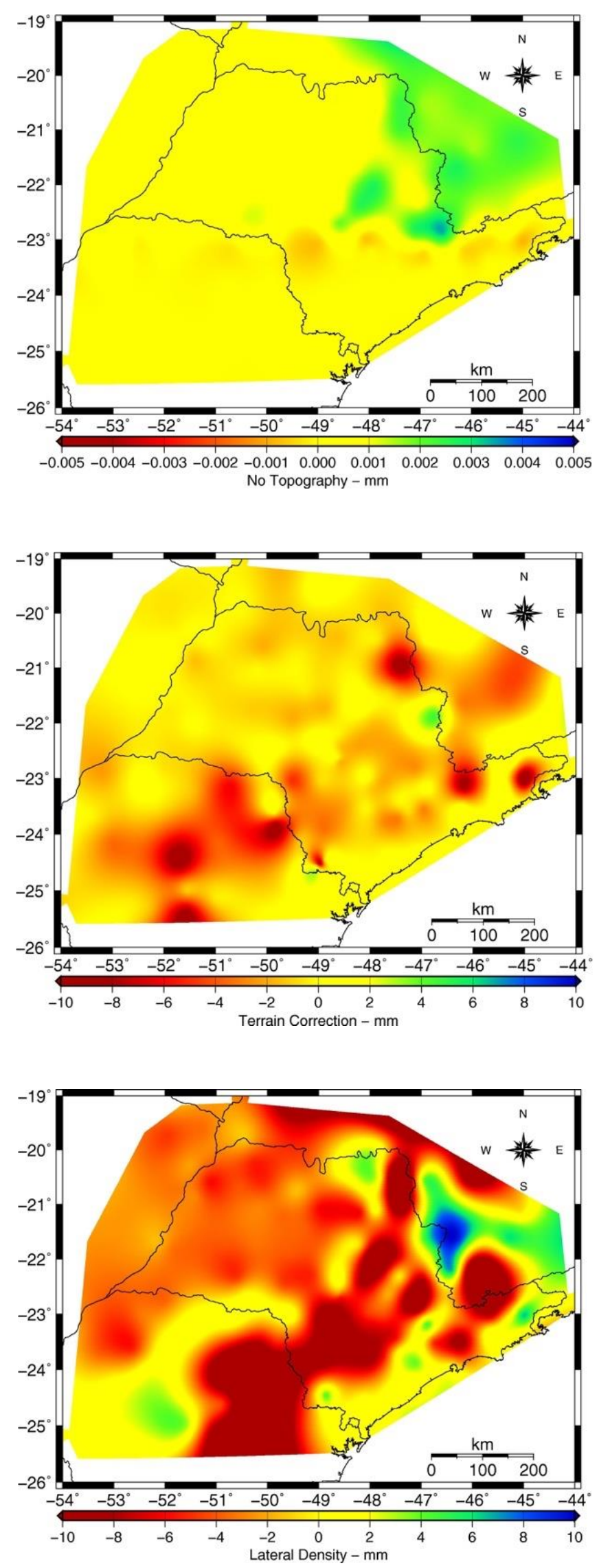

Figure 6: Corrections applied on Helmert's orthometric heights 
We can see in Figure 7 the relationship between the total correction applied to the heights and the elevation of the points. The methodology used to obtain the rigorous orthometric height, is somewhat related to the topography, i.e., the larger elevations the larger correction. Looking at Figure 7, the corrections at lower elevations, between 0 and 400 meters (coast of Brazil), are very small, having a maximum of approximately 6 millimeters. The corrections increase in the mountainous area having maximum correction values of $\sim 10$ and minimum of -30 millimeters.

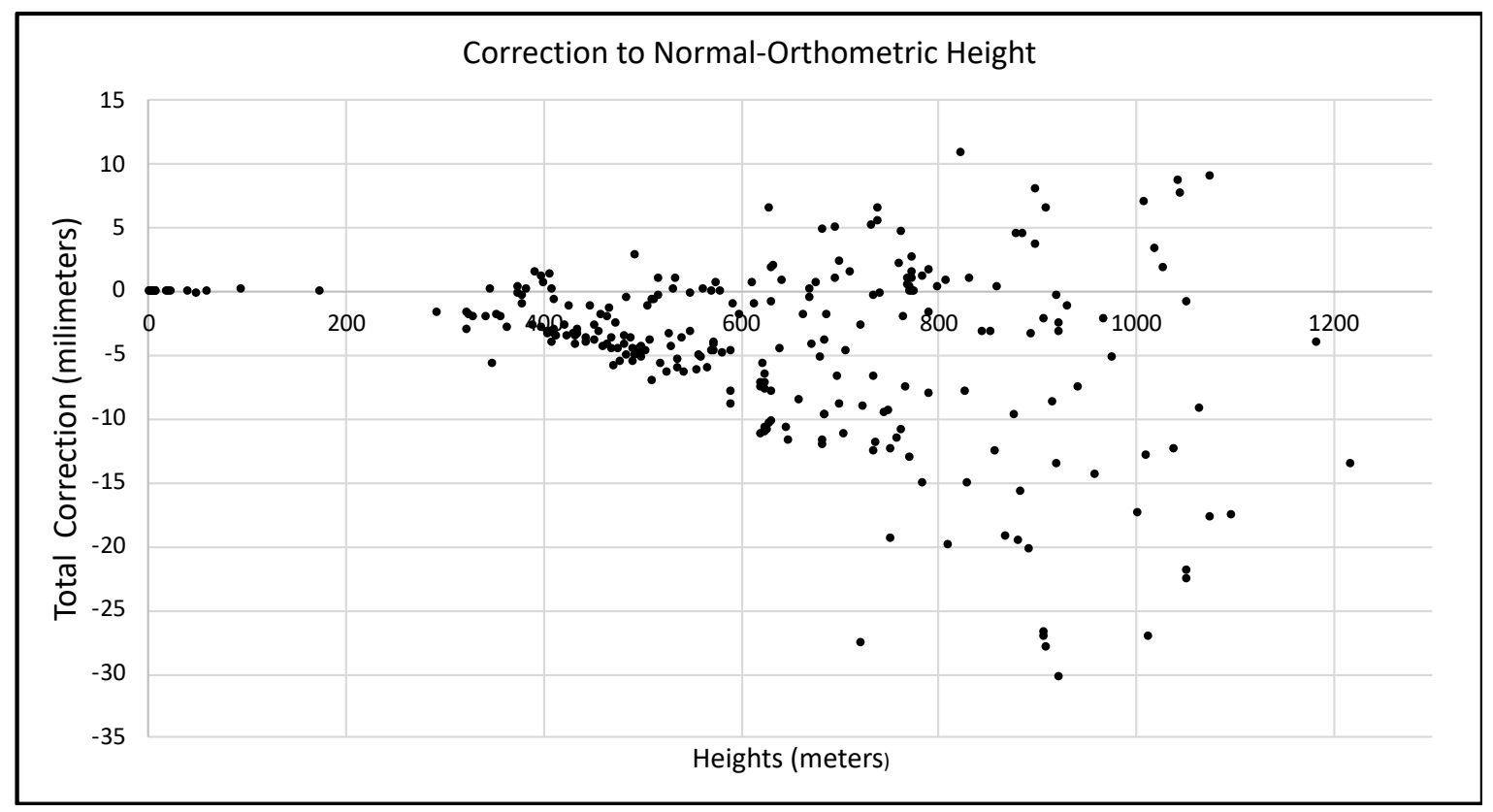

Figure 7: Correction to the Rigorous orthometric height

In order to identify and quantify the differences between the normal-orthometric height $\left(H^{N O}\right)$ to Helmert's orthometric heights $\left(H^{O}\right)$ and rigorous orthometric height $\left(H^{R O}\right)$, the statistics are presented for these differences in Table 2. When analyzing Table 2, it is possible to observe the differences between the statistics $\left(H^{O}-H^{N O}\right.$ and $\left.H^{R O}-H^{N O}\right)$. The differences have minimum and maximum values of $-0.004 \mathrm{~m}$ and $0.01 \mathrm{~m}$, respectively, and they have a limited impact on the corrected height. Nevertheless, when applying the corrections the value of the overall standard-deviation decreases.

Table 2: Resulting statistics (Difference between Normal-Orthometric height to Helmert and Rigorous orthometric height)

\begin{tabular}{c|c|c|c|c}
\hline Statistics & $\operatorname{Min}(\mathrm{m})$ & $\operatorname{Max}(\mathrm{m})$ & Mean $(\mathrm{m})$ & Std $( \pm)(\mathrm{m})$ \\
\hline$\left(H^{o}-H^{N O}\right)$ & -0.721 & 0.478 & -0.320 & 0.197 \\
$\left(H^{R O}-H^{N O}\right)$ & -0.725 & 0.468 & -0.325 & 0.195 \\
\hline
\end{tabular}

Figure 8 shows the difference between the rigorously determined orthometric height and the normal-orthometric height, the major differences (red scale) are in the mountainous region of the state of São Paulo and Paraná. The values for the study area is between 0.47 and -0.72 meters. 


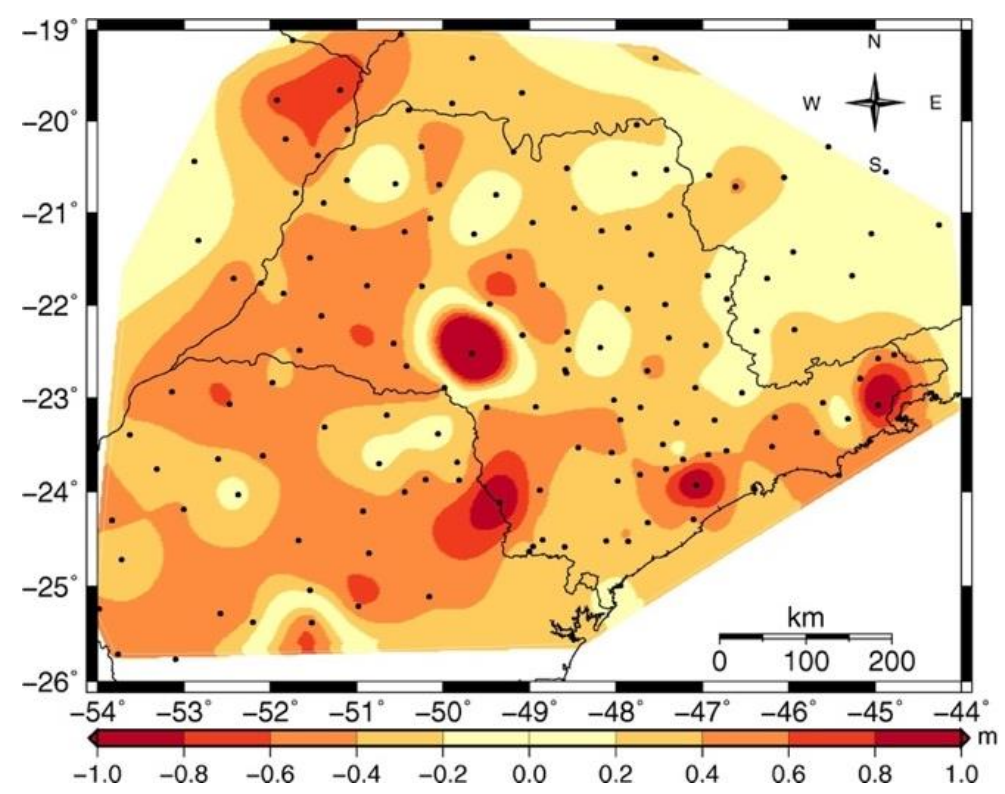

Figure 8: Difference between Normal-Orthometric height and Rigorous orthometric height

To better illustrate the differences on the heights system we compared the difference between the rigorous orthometric heights to Normal height and Normal-Orthometric heights (component heights of the Brazilian Geodetic System until July 2018) to Normal heights. Figure 9 and 10 illustrate these differences, respectively, and Table 3 presents the statistical values.

Table 3: Resulting statistics (difference to Normal height)

\begin{tabular}{c|c|c|c|c}
\hline Statistics & $\operatorname{Min}(\mathrm{m})$ & $\operatorname{Max}(\mathrm{m})$ & Mean $(\mathrm{m})$ & $\operatorname{Std}( \pm)(\mathrm{m})$ \\
\hline Normal-Ortometric $\left(H^{N O}\right)$ & -0.491 & 1.244 & 0.376 & 0.183 \\
Rigorous Ortometric $\left(H^{R O}\right)$ & -0.049 & 0.371 & 0.043 & 0.041 \\
\hline
\end{tabular}
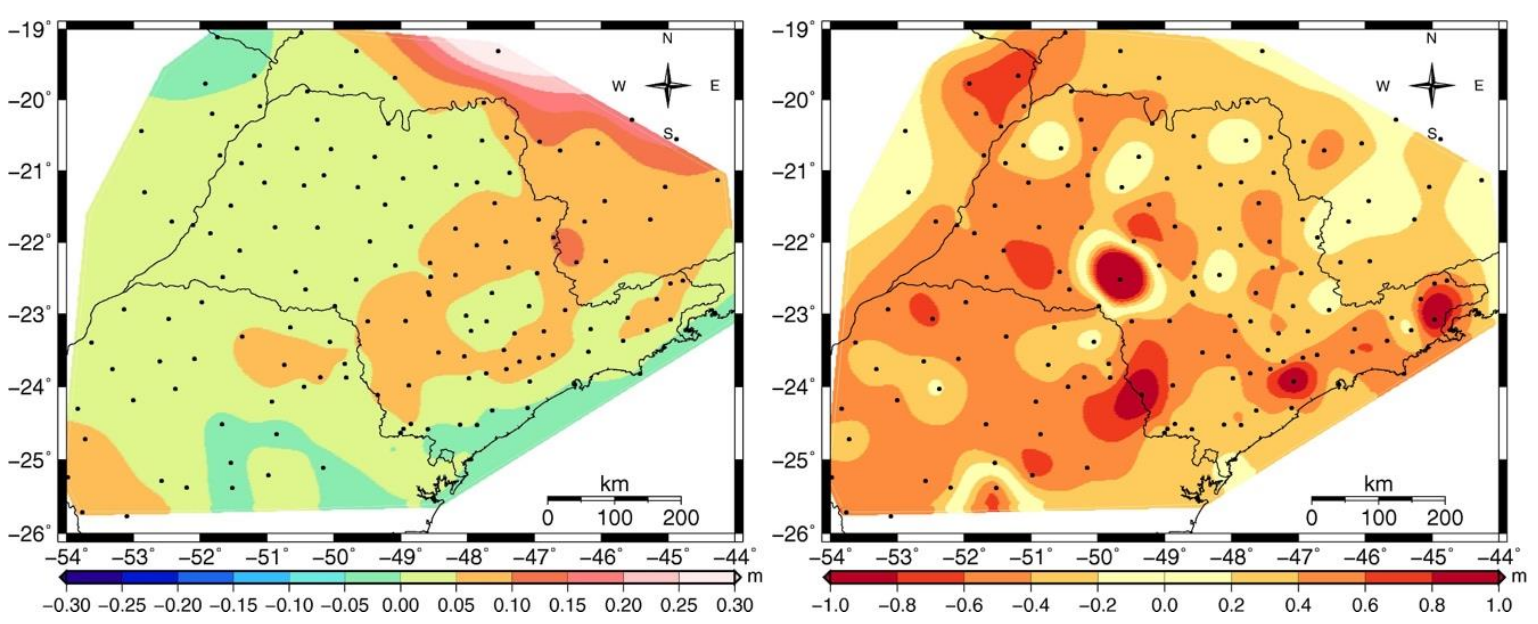

Figure 9: (Left) Difference between the Rigorous Orthometric Height and Normal Height and (Right) Difference between the Normal-Orthometric Height and Normal Height (Units in meters) 


\section{Conclusion}

Approximating the mean gravity along the plumbline (equation 15) is essential to determine the rigorous orthometric height and can be decomposed into five corrections: second order to normal gravity and Bouguer shell, geoid-generated gravity disturbance (no-topography), terraingenerated gravity and the lateral variation for the density of topographic masses. These five effects were calculated separately and each of them was used throughout the state of São Paulo (Figure 6). From this we can verify that the corrections varied according to the height variation (Figure 7). We determined a system for the rigorously determined orthometric height in 155 points throughout the São Paulo state. These control points also have normal-orthometric heights and are already corrected for non-parallelism (Equation 1).

We compared the statistics obtained from each correction and the lateral density variation of topographic masses was the correction that contributed the most, followed by the terraingenerated gravity. This was expected since the characteristics of the terrain varied greatly, going from the coast to the interior of the state, for example. The third largest contribution was the geoid-generated gravity. The second-order to normal gravity and the Bouguer shell were the two corrections that contributed the least, however, they were not excluded from our study. In Foroughi et al. 2017, these corrections were excluded, but in Santos et al. (2006), they were computed. The reason for this is that these corrections are related to the heights of the points.

Based on the numerical tests for the state of São Paulo and adjacent states, we can conclude three distinct parts:

The first and most important is that the five calculated corrections should only be applied to Helmert's orthometric heights. The second and not less important is that the normal-orthometric height system is not the most suitable for the state of São Paulo, the tests indicated a large difference between this system and the normal system (Table 3). The obtained values (Table 2) show the differences of the normal-orthometric height to Helmert's and rigorous orthometric height, it can be seen that the differences are not discrepant, because the corrections applied to the heights are also not large, having minimum values and maximum of $\square-28 \mathrm{~mm}$ and $\square 13 \mathrm{~mm}$, respectively (Table 1 ).

Third, when analyzing the behavior between the Normal and Rigorous orthometric heights, it is verified that the values are smaller, which means to say that this new system of height calculated is more appropriate, since, according to Ferreira et al. (2011), the knowledge of the separation between the geoid and the quasi-geoid with precision in the order of the centimeter, is essential for the realization of modern vertical reference networks. Thus, it is verified that rigorous orthometric height is the one that best behaves in the São Paulo state.

This study showed that to determine the rigorous orthometric height the terrain/roughness and the normal gravity are not the only effects to be considered, the additional effects from masses contained within the geoid and from the variations of mass density within the topographic surface are also important. These effects must be considered because the mean gravity value along the plumbline between the geoid and the surface of the Earth depends of these values. Finally, the objectives of calculating the corrections to the Helmert heights were met in this paper, verifying their behavior and quantifying the differences between rigorous orthometric height and the normal-orthometric heights, as well as verifying the differences between both systems with normal height system. 


\section{Acknowledgement}

The authors would like to thank CAPES (PDSE process $n^{\circ} 88881.132305 / 2016-1$ ) for the scholarship granted, FEC/Unicamp and Department of Geodesy and Geomatics Engineering at the University of New Brunswick for the support during the exchange scholarship, and IFSULDEMINAS for the license of the main author to develop the doctorate.

\section{REFERENCES}

Allister, N. and Featherstone, W. 2001. Estimation of Helmert orthometric heights using digital barcode levelling, observed gravity and topographic mass-density data over part of Darling Scarp,Western Australia, Geomat. Res. Aust., 75, 25-52.

Albarici, F. L., I. Foroughi., M. Santos., G.N. Guimarães., J.L.A. Trabanco., R. Kingdon and P. Vanicěk. 2017. Study of Corrections to obtain the Rigorous Orthometric Height. In: XXVII Congresso Brasileiro de Cartografia, 2017, Rio de Janeiro. Disponível em: <http://www.cartografia.org.br/cbc/Programa-CBC-2017v5.pdf>. Access on: Dec. 14, 2017.

Amos, M. J. and Featherstone, W. E. 2009. Unification of New Zealands local vertical datums: iterative gravimetric quasigeoid computations. J Geodesy 83(1):57-68.

Bomford, G. 1980. Geodesy, 4th edn. Oxford University Press, Oxford.

Blitzkow, D., I. O. Campos and S. R. C. de Freitas. 2007. Altitude: O que interessa e como equacionar?. Departamento de Engenharia de Transportes - Escola Politécnica, Universidade de São Paulo, São Paulo. 153 p.

Ferreira, V. G. 2011. Solução do tipo Brovar para o segundo problema de valor de contorno da geodésia com vistas à modernização de sistemas de altitudes. 2011. 171f. Tese (doutorado) Universidade Federal do Paraná, Setor de Ciências da Terra, Programa de Pós-Graduação em Ciencias Geodésicas. Defesa: Curitiba. Available at: <http://hdl.handle.net/1884/25954>. [Accessed 9 April 2018].

Ferreira, V. G., Freitas, S.R.C. and Heck, B. 2011. A separação entre o geoide e o quase-geiode: uma análise no contexto brasileiro. Revista Brasileira de Cartografia, Vol. 63, pp. 39-50.

Filmer, M. S., Featherstone, W. E. and Kuhn, M. 2010.The effect of EGM2008- based normal, normal-orthometric and Helmert orthometric height systems on the Australian levelling network. Journal of Geodesy, v. 84, N. 8, pp. 501-513.

Foroughi, I. and Tenzer, R. 2017. Comparison of different methods for estimating the geoid-toquasigeoid separation. Geophysical journal international, 210, pp 1001-1020 
Foroughi, I. et al. 2015. The effect of lateral topographical density variations on the geoid in Auvergne, in 26th IUGG General Assembly, Prague, Czech Republic.

Foroughi, I., P. Vanicěk., Sheng, M., R. Kingdon and Santos, M. 2017. In defense of the classical height system. Geophysical Journal International. DOI: 10.1093/gji/ggx366.

Foroughi, I., Santos, M., Kingdon, R., Vanicek, P. 2018. Rigorous Orthometric Heights: theoretical overview and advantages of use. EGU general assembly, Vienna, Austria.

Förste, C. et al. 2014. EIGEN-6C4: the latest combined global gravity field model including GOCE data up to degree and order 2190 of GFZ Potsdam and GRGS Toulouse, Presented at the 5th GOCE User Workshop, Paris, 2014 November 25-28.

Freitas, S. R. C. and Blitzkow, D. 1999. Altitudes e geopotencial. Iges Bulletin, Milão, n. 9, p. 4761.

Heiskanen, W.A. and Moritz, H. 1967. Physical Geodesy, W. H. Freeman, San Francisco, CA, 364p.

Hirt, C. and Rexer, M. 2015. Earth 2014: 1 arc-min shape, topography, bedrock and ice-sheet models - available as gridded data and degree- 10,800 spherical harmonics, Int. J. Appl. Earth Obs. Geoinf., 39, 103-112.

Hofmann-Wellenhof, B, and Moritz, H. 2006. Physical Geodesy. Springer-Verlag, Berlin, 397p.

IBGE, 2011. Ajustamento simultâneo da Rede Altimétrica de Alta Precisão do Sistema Geodésico Brasileiro. IBGE, Rio de Janeiro, 60 páginas. [on line] Available at:<ftp://geoftp.ibge.gov.br/informacoes_sobre_posicionamento_geodesico/rede_altimetrica/re latorio/relatorioajustamento.pdf> [Accessed 13 October 2016].

IBGE, 2015. Resolução do Presidente do IBGE № 1/2015 - Define a data de término do período de transição definido na RPR 01/2005 e dá outras providências sobre a transformação entre os referenciais geodésicos adotados no Brasil, IBGE, Rio de Janeiro. [on line] Available at:<ftp://geoftp.ibge.gov.br/metodos_e_outros_documentos_de_referencia/normas/nota_tecni ca_termino_periodo_transicao_sirgas2000.pdf> [Accessed 26 March 2018].

Kingdon, R. et al. 2005. Toward an improved orthometric height system for Canada. Geomatica, 59(3)., pp 241-250 (Errata: Figure 4 on Geomatica,Vol 60 (1):101).

Meyer, T. H. Roman, D. R. and Zilkoski, D. B. 2006. What Does Height Really Mean? Part III: Height Systems, Surveying and Land Information Science,. Vol. 66, No.2, pp.149-160.

Molodensky M. S. 1945. Fundamental problems of geodetic gravimetry (in Russian). TRUDY Ts NIIGAIK, vol. 42, Geodezizdat, Moscow.

Molodensky M. S. 1948. External gravity field and the shape of the Earth surface (in Russian). Izv. CCCP, Moscow.

Odera, P. and Fukuda,Y. 2015. Comparison of Helmert and rigorous orthometric heights over Japan, Earth Planets Space, 67(27), doi:10.1186/s40623-015-0194-2. 
Pina, W. H. et al. 2006. Reajustamento Global da Rede Altimétrica de Alta Precisão do Brasil RAAP. IV Conferência Nacional de Geociências, Rio de Janeiro.

SIRGRAS, 2018. Geocentric Reference System for the Americas. [on line] Available at:

<http://www.sirgas.org/en/sirgas-definition/> [Accessed 26 March 2018].

Santos, M.C. et al. 2006, The relation between Rigorous and Helmert's definition of orthometric heights - Jornal Geodesy, 80, pp. 691-704

Sánchez, L. 2013. Towards a vertical datum standardisation under the umbrella of Global Geodetic Observing System. Journal of Geodetic Science 2(4): 325-342, Versita, 10.2478/v10156012-0002-x.

Tenzer, R., Vaníček, P., Santos, M. C., Featherstone, W. E and Kuhn, M. 2005. The rigorous determination of orthometric heights - Jornal. Geodesy, n 79, pp. 82-92.

Tenzer, R. et al. 2015. Spatial and spectral representations of the geoid-to-quasigeoid correction. Surv. Geophys., 36, 627-658.

Vaníček, P. et al. 2003. Algunos aspectos sobre alturas ortométricas y normales. Revista Cartográfica, $n^{\circ} .76 / 77$, pp. 79-86. 